Check for updates

Cite this: RSC Adv., 2019, 9, 24110

\title{
Cerium(III) complexes with azolyl-substituted thiophenolate ligands: synthesis, structure and red luminescence $\uparrow$
}

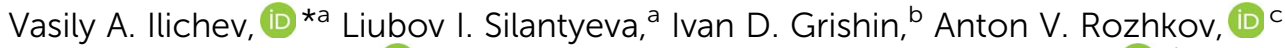 \\ Roman V. Rumyantcev, (iD ${ }^{a}$ Georgy K. Fukin ${ }^{a}$ and Mikhail N. Bochkarev (D) ab
}

In order to obtain molecular Ce(III) complexes which emit red light by $\mathrm{f}$-d transitions the azolyl-substituted thiophenolates were used as the ligands. The thiophenolate Ce(III) complexes were synthesized by the reaction of $\mathrm{Ce}\left[\mathrm{N}\left(\mathrm{SiMe}_{3}\right)_{2}\right]_{3}$ with respective thiophenols 2-(2'-mercaptophenyl)benzimidazole (H(NSN)), 2(2'-mercaptophenyl)benzoxazole $(\mathrm{H}(\mathrm{OSN}))$ and 2-(2'-mercaptophenyl)benzothiazole $(\mathrm{H}(\mathrm{SSN}))$ in DME media. The structures of the benzimidazolate $\left(\mathrm{Ce}(\mathrm{NSN})_{3}(\mathrm{DME})\right)$ and benzothiazolate $\left(\mathrm{Ce}(\mathrm{SSN})_{3}(\mathrm{DME})\right)$ derivatives were determined by $\mathrm{X}$-ray analysis which revealed that the cerium ion in the molecules is coordinated by one DME and three anionic thiophenolate ligands. The lanthanum complex $\mathrm{La}(\mathrm{OSN})_{3}(\mathrm{DME})$ has been synthesized similarly and structurally characterized. It was found that the solids of $\mathrm{Ce}(\mathrm{SSN})_{3}(\mathrm{DME})$ and $\mathrm{Ce}(\mathrm{OSN})_{3}(\mathrm{DME})$ exhibit a broad band photoluminescence peaking at $620 \mathrm{~nm}$ which disappears upon solvatation. With an example of OSN derivatives it was proposed that this behaviour is caused by the blue shift of the $\mathrm{f}-\mathrm{d}$ transition of $\mathrm{Ce}^{3+}$ ions.

Received 29th April 2019

Accepted 30th July 2019

DOI: 10.1039/c9ra03199e

rsc.li/rsc-advances
A new surge of interest in luminescent trivalent cerium complexes is directly associated with the discovery of photoredox catalytic activity of these compounds in some reactions. ${ }^{\mathbf{1 4 - 1 6}}$ The most active photoredox-catalytic complexes are luminescent derivatives of ruthenium and iridium, which have long-lived triplet excited states. ${ }^{17-20}$ In the case of Ce(III) complexes the existence of relatively long-lived excited states is attributed to $5 \mathrm{~d}$ states of the cerium ion. The energies of $5 \mathrm{~d}$ states, in contradistinction to $4 \mathrm{f}$ states, are extremely sensitive to ligand environment. It is known that some cerium complexes with silylamide, ${ }^{21}$ guanidinate, aryloxide,${ }^{15}$ alkoxide,$^{22}$ cyclopentadienyl, ${ }^{23-25}$ tripodal,${ }^{26,27}$ carboxylate, ${ }^{28,29}$ bipyridyl, ${ }^{30}$ Schiff-base $^{31}$ and crown-ether ${ }^{32}$ ligands exhibit the PL in the range from near ultraviolet (UV) to yellow colour. To the best of our knowledge the red luminescent Ce(III) complexes are still unknown.

It was showed by Dorenboos that the energy and wavelength of $\mathrm{f}-\mathrm{d}$ transitions of the Ce(III) ions doped in inorganic hosts varies in the range from near UV to red light. ${ }^{33-35}$ Noticeable, that the lowest energies and maximal wavelengths of these transitions are observed in sulphide matrices. Therefore, it is reasonable to expect that the $\mathrm{Ce}$ (III) molecular complexes with organosulphide ligands could emit red light. Such compounds can be used as red luminophores as well as potential photoredox catalysts which efficiently harvest the visible light. In present work we have used a set of azolyl-substituted thiophenolates to be applied as ligands for the design of red luminescent $\mathrm{Ce}(\mathrm{III})$ molecular complexes. 


\section{Results and discussion}

In order form novel cerium complexes we have used the thiophenols which contain in $o$-position the heterocyclic substituents - 2-benzimidazolyl (H(NSN)), 2-benzoxazolyl (H(OSN)) and 2-benzothiazolyl (H(SSN)). The reaction of the cerium silylamide complex with respective thiophenols readily proceeds at room temperature in DME media (Scheme 1) resulting in a formation of targeted complexes in good yields. In case of benzimidazolyl-substituted thiophenol (H(NSN)) an ultrasonic treatment was applied because of poor solubility of H(NSN) in DME. The Ce(III) complexes were isolated as air-sensitive orange or yellow-orange powders.

In cases of benzimidazolyl and benzothiazolyl derivatives the X-ray suitable crystals of the cerium complexes were grown. However, all the attempts to obtain such crystals for the benzoxazolyl derivative were failed. In order to study the structure by X-rays the lanthanum analogue of OSN-based complex was synthesized similarly to Scheme 1 but with the use of La $\left[\mathrm{N}\left(\mathrm{SiMe}_{3}\right)_{2}\right]_{3}$ as the rare-earth precursor. The X-ray suitable crystals of this lanthanum complex were successfully grown. According to X-ray data, the lanthanide complexes have a similar molecular structure. These complexes are monomers in which the $\mathrm{Ln}^{3+}$ cations are coordinated by three SSN $\left(\mathrm{Ce}(\mathrm{SSN})_{3}(\mathrm{DME})\right)$, NSN $\left(\mathrm{Ce}(\mathrm{NSN})_{3}(\mathrm{DME})\right)$ and OSN $\left(\mathrm{La}(\mathrm{OSN})_{3}(-\right.$ DME)) ligands and one neutral molecular DME (Fig. 1). Thus, the coordination number of each lanthanide atom in these complexes is eight, and the coordination environment of $\mathrm{Ln}^{3+}$ is a distorted square antiprism (Fig. 2).

The $\mathrm{S}(1) \mathrm{S}(5) \mathrm{N}(1) \mathrm{N}(2)$ and $\mathrm{S}(3) \mathrm{N}(3) \mathrm{O}(1) \mathrm{O}(2)$ planes in $\mathbf{C e}(\mathrm{SSN})_{3}$ (DME), the $\mathrm{S}(1) \mathrm{S}(3) \mathrm{N}(1) \mathrm{N}(3)$ and $\mathrm{S}(2) \mathrm{N}(5) \mathrm{O}(1) \mathrm{O}(2)$ planes in $\mathbf{C e}(\mathbf{N S N})_{3}($ DME) and the $\mathrm{S}(1) \mathrm{S}(3) \mathrm{N}(1) \mathrm{N}(2)$ and $\mathrm{S}(2) \mathrm{N}(3)$ $\mathrm{O}(4) \mathrm{O}(5)$ ones in $\mathbf{L a}(\mathbf{O S N})_{3}(\mathbf{D M E})$ are located almost parallel to each other. The dihedral angles between these planes are $8.96^{\circ}$, $8.50^{\circ}$ and $11.64^{\circ}$ in $\mathrm{Ce}(\mathrm{SSN})_{3}(\mathrm{DME}), \mathrm{Ce}(\mathrm{NSN})_{3}(\mathrm{DME})$ and La(OSN) $)_{3}$ (DME), respectively.

The NSN, SSN and OSN ligands in these complexes are largely non-flat. Such geometry is characteristic of related ligands. ${ }^{36}$ The dihedral angles between the thiophenolate and benzothiazolyl, benzimidazolyl and benzoxazolyl fragments are $38.93 \div 56.13^{\circ}$, $40.29 \div 49.77^{\circ}$ and $21.06 \div 25.69^{\circ}$, respectively.

It is interesting to note that the NSN and OSN ligands in $\mathbf{C e}(\mathbf{S S N})_{3}(\mathrm{DME})$ and $\mathbf{L a}(\mathrm{OSN})_{\mathbf{3}}$ (DME) complexes are arranged in such a way that the planes of the five-membered heterocycle of one ligand (A, D) and the phenyl ring of the thiophenolate fragment of the second ligand $(\mathrm{B}, \mathrm{C})$ are almost parallel to each other (the dihedral angles are $15.62^{\circ}(\mathrm{A} \cdots \mathrm{B}), 27.02^{\circ}(\mathrm{C} \cdots \mathrm{D})$ and

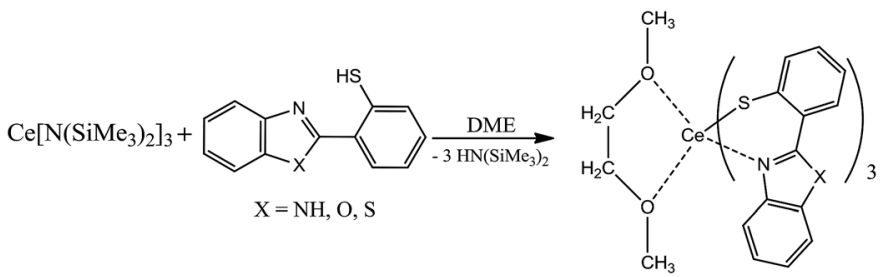

Scheme 1
$16.21^{\circ}(\mathrm{A} \cdots \mathrm{B}), 12.20(\mathrm{C} \cdots \mathrm{D})$ in $\mathrm{Ce}(\mathrm{SSN})_{3}(\mathrm{DME})$ and $\mathbf{L a}(\mathrm{OSN})_{3}(-$ DME), respectively), and the distances between the centers of these fragments are $3.376 \AA(\mathrm{A} \cdots \mathrm{B}), 3.639 \AA(\mathrm{C} \cdots \mathrm{D})$ and $3.583 \AA$ $(\mathrm{A} \cdots \mathrm{B}), 3.528 \AA(\mathrm{C} \cdots \mathrm{D})$ in $\mathrm{Ce}(\mathrm{SSN})_{3}(\mathrm{DME})$ and $\mathbf{L a}(\mathrm{OSN})_{3}(\mathrm{DME})$, respectively (Fig. 1a and c). These geometrical parameters indicate the presence of intramolecular $\pi \cdots \pi$ interactions in both complexes. ${ }^{37}$ Unlike them, in the $\mathbf{C e}(\mathbf{N S N})_{3}$ (DME) complex, the corresponding values are $3.712 \AA$ and $25.52^{\circ}(\mathrm{A} \cdots \mathrm{B}), 3.891 \AA$ and $35.62^{\circ}$ (C)D) (Fig. 1b). Such values slightly exceed the geometric criterion for the presence of pi-pi interactions. ${ }^{37}$

The Ce-S distances in $\mathbf{C e}(\mathbf{S S N})_{3}(\mathrm{DME})$ and $\mathbf{C e}(\mathbf{N S N})_{3}(\mathrm{DME})$ lie in the range of $2.8588(8) \div 2.9330(11) \AA$ and these values are in a good agreement both with each other and with previously published cerium complexes containing thiophenolate fragments. $^{38-40}$ The coordination bonds of $\mathrm{Ce}-\mathrm{N}$ and $\mathrm{Ce}-\mathrm{O}$ in complexes $\mathrm{Ce}(\mathrm{SSN})_{3}(\mathrm{DME})$ and $\mathrm{Ce}(\mathrm{NSN})_{3}(\mathrm{DME})$ vary over a wider range $(2.549(4) \div 2.891(3) \AA(\mathrm{Ce}-\mathrm{N})$ and $2.568(2) \div$ 2.661(2) A (Ce-O)) (Table 2S $\dagger$ ). All Ln-X (X= S, N, O) distances (Table $2 S^{\dagger}$ ) in complex $\mathbf{L a}(\mathbf{O S N})_{3}(\mathbf{D M E})$ are also in the range of values characteristic for lanthanum complexes. ${ }^{\mathbf{4 0 - 4 2}}$

Despite the large number of aromatic systems in the SSN, NSN and OSN ligands, intermolecular $\pi \cdots \pi$ interactions in all structurally characterized complexes are not detected. It is interesting to note that the molecules of $\mathbf{C e}(\mathbf{N S N})_{3}$ (DME) form a dimeric pair in a crystal (Fig. 3). The ligands of neighboring molecules are arranged in such a way that the distance between the nitrogen atom of one ligand and the sulfur atom of the other ligand is $3.375 \AA$. This value indicates the existence of the $\mathrm{N}-\mathrm{H} \cdots \mathrm{S}$ interaction. ${ }^{43}$

The structure of $\mathrm{Ce}(\mathrm{OSN})_{3}(\mathrm{DME})$ was not determined by Xrays but the elemental analysis, similarity of the MALDI-TOF spectra of this compound and its lanthanum counterpart and identity of IR spectra of the $\mathrm{La}(\mathrm{III})$ and $\mathrm{Ce}(\mathrm{III})$ complexes indicate that the complex $\mathbf{C e}(\mathbf{O S N})_{3}(\mathbf{D M E})$ has a similar structure to its lanthanum analogue. The most intensive signals in massspectra of complexes $\mathrm{Ce}(\mathrm{SSN})_{3}(\mathrm{DME}), \mathbf{L a}(\mathrm{OSN})_{3}(\mathrm{DME})$ recorded in positive mode (Fig. 1Sa†) are ones corresponding to $\mathrm{ML}_{2}^{+}$ and $\mathrm{M}_{2} \mathrm{~L}_{5}{ }^{+}$species. The molecules of DME do not present in the structures of the formed ions indicating its weak coordination. It should be mentioned that the mass spectrum of $\mathbf{L a}(\mathbf{O S N})_{3}(-$ DME) is similar to the spectrum of another complexes and contains the same peaks corroborating the identical structure of the complex. The spectra of these compounds recorded in negative mode depicted on the figure of $1 \mathrm{Sb} \dagger$ are also similar and contain identical signals of $\mathrm{M}_{x} \mathrm{~L}_{y}{ }^{-}$- type ions. The presence of additional sulfur and oxygen atoms may be result of partial decomposition of DME or ligand under laser impact.

The complexes $\mathbf{C e}(\mathbf{O S N})_{3}(\mathbf{D M E})$ and $\mathbf{C e}(\mathbf{S S N})_{3}(\mathrm{DME})$ in the solid state exhibit PL in the red range of visible light (Fig. 4). While the complex $\mathbf{C e}(\mathbf{N S N})_{\mathbf{3}}$ (DME) is non-luminescent. The broad shape of the spectra, the location in the red region of the spectrum and the independence of the emission intensities from the temperature indicate the $f-d$ nature of the PL. The absence of such PL in the case of benzimidazole derivative is caused, apparently, by quenching effect of hydrogen bounds.

But in the DME solutions the observed red PL of the Ce(III) complexes disappears. In order to understand this feature, it is reasonable to use the lanthanum derivatives as reference 

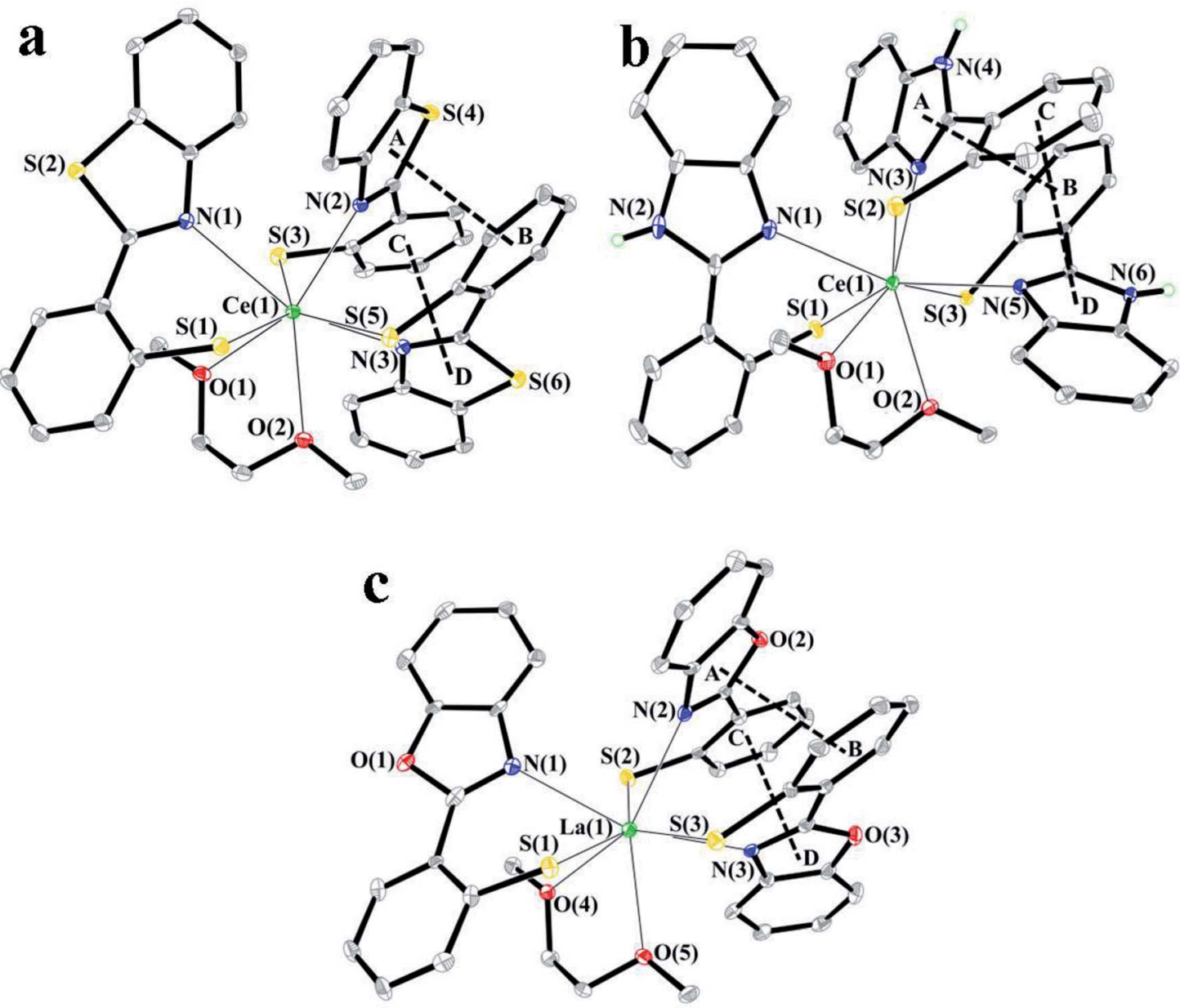

Fig. 1 Molecular structures of complexes $\mathrm{Ce}(\mathrm{SSN})_{3}(\mathrm{DME})(\mathrm{a}), \mathrm{Ce}(\mathrm{NSN})_{3}(\mathrm{DME})(\mathrm{b})$ and $\mathrm{La}(\mathrm{OSN})_{3}(\mathrm{DME})$ (c). The probability ellipsoids are drawn at the $30 \%$ level. The hydrogen atoms are omitted for clarity.

complexes. A comparison of the optical properties of lanthanum and cerium complexes has been provided with an example of OSN ligand. The complex La(OSN) $)_{3}(\mathbf{D M E})$ exhibit a broad band PL peaked at $500-530 \mathrm{~nm}$ in solid state (Fig. $2 \mathrm{~S} \dagger$ ). The PL behavior in DME solution of both (La and Ce) complexes is similar to their Gd counterpart. ${ }^{36}$ As one can see from a photo of the samples of $\mathbf{L a}(\mathbf{O S N})_{3}(\mathrm{DME})$ and $\mathrm{Ce}(\mathrm{OSN})_{3}(\mathrm{DME})$ the compounds have different color (Fig. 5).

This difference, evidently, is caused by the $\mathrm{f}-\mathrm{d}$ absorption of $\mathrm{Ce}^{3+}$ ions. Orange color corresponds to the absorption in the bluishgreen region at about $500 \mathrm{~nm}$. However, in the DME solutions the absorption spectra of both compounds are almost identical, no absorption at $500 \mathrm{~nm}$ is observed for the cerium complex. Apparently, this behavior is caused by a shifting of the $\mathrm{f}-\mathrm{d}$ absorption towards blue region upon solvatation. It is known that the energy of $\mathrm{f}-\mathrm{d}$ transitions in free $\mathrm{Ce}^{3+}$ ion corresponds to $\mathrm{UV}$ region and it can be only red shifted by the crystal field of the ligands. ${ }^{33}$ The most powerful shifters are sulphides. Consequently, the solvatation and dissociation of cerium organosulphide complexes may result only in blue shift of the $\mathrm{f}-\mathrm{d}$ transitions. It is important to note that typical values of absorption coefficients range at hundreds of $\mathrm{L}$ $\mathrm{mol}^{-1} \mathrm{~cm}^{-1}$ (ref. 44) for $\mathrm{f}-\mathrm{d}$ transitions of $\mathrm{Ce}^{3+}$ while absorption of the substituted thiophenolates exceed thousands of $\mathrm{L}$ $\mathrm{mol}^{-1} \mathrm{~cm}^{-1} \cdot{ }^{36}$ As a result of overlapping of these absorption bands the orange color of $\mathbf{C e}(\mathbf{O S N})_{3}(\mathbf{D M E})$ virtually disappears in the solution.

\section{Experimental}

\section{General procedures}

All manipulations were carried out under vacuum using standard Schlenk techniques or in an argon glove box $\left(\mathrm{H}_{2} \mathrm{O}<\right.$ $\left.0.1 \mathrm{ppm} ; \mathrm{O}_{2}<1 \mathrm{ppm}\right)$. The reagents including thiosalicylic acid, polyphosphoric acid, $o$-aminophenol, $o$-aminothiophenol, $o$-phenylenediamine, lanthanum and cerium amides $\mathrm{Ln}\left[\mathrm{N}\left(\mathrm{SiMe}_{3}\right)_{2}\right]_{3}$ (95-98\% purity) were purchased from commercial sources and used as received. The solvents 1,2dimetoxyethane (DME), hexane and toluene were dried by refluxing over sodium for $12 \mathrm{~h}$. The $\mathrm{C}, \mathrm{H}, \mathrm{N}$ and $\mathrm{S}$ elemental analyses were performed on a Euro EA 3000 elemental analyser. The lanthanide contended was analysed by complexometric titration. IR spectra were obtained on a PerkinElmer 577 spectrometer and recorded from 4000 to $450 \mathrm{~cm}^{-1}$ as a Nujol mull on KBr plates. Photoluminescence 

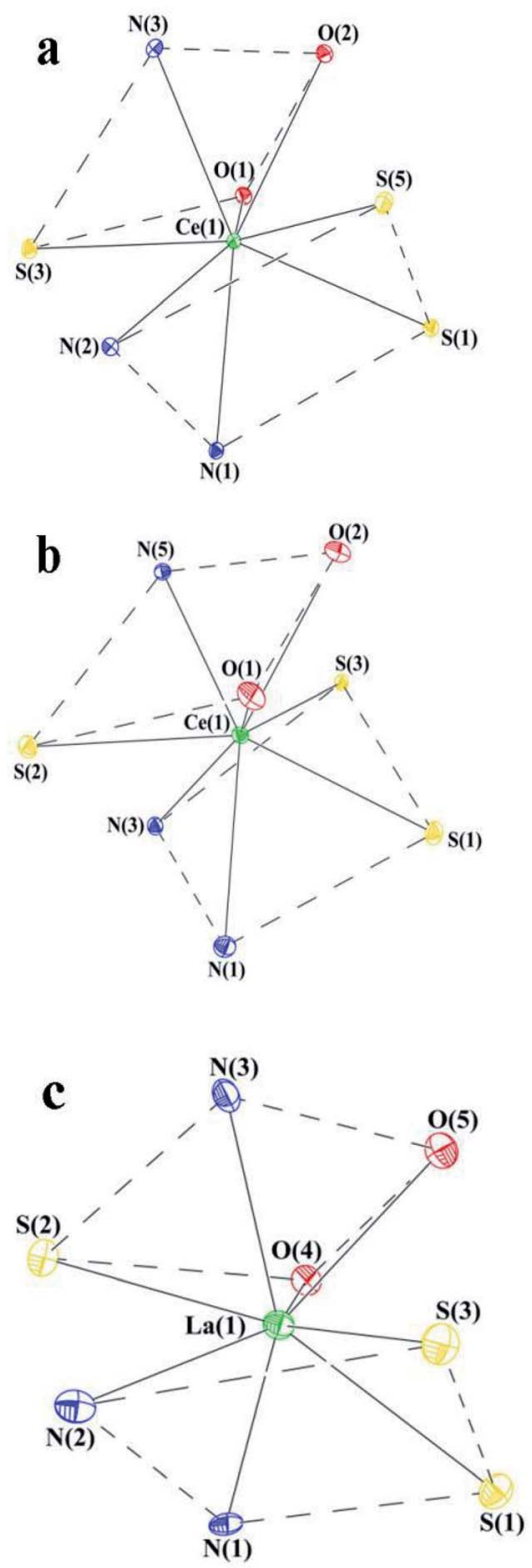

Fig. 2 The coordination environment of $\mathrm{Ln}$ in complexes $\mathrm{Ce}(\mathrm{SSN})_{3}(-$ DME) (a), Ce(NSN) $)_{3}$ (DME) (b) and $\mathrm{La}(\mathrm{OSN})_{3}(\mathrm{DME})$ (c).

of solid samples was excited with a $100 \mathrm{~mW}, 405 \mathrm{~nm}$ laser diode or $365 \mathrm{~nm}$ UV diode and detected in a region 365$1000 \mathrm{~nm}$ with Ocean Optics USB2000 spectrometer. The spectroscopic measurements of the compounds were performed in DME solution using a $1 \mathrm{~cm}$ vacuumed quartz cell. The absorption spectra were recorded with a PerkinElmer Lambda $25 \mathrm{UV} /$ VIS spectrometer from 200 to $800 \mathrm{~nm}$. The PL and PLE spectra were recorded with a PerkinElmer LS 55 fluorescence spectrometer. MALDI-TOF mass-spectra of the compounds were obtained on a Bruker Microflex LT spectrometer equipped with a nitrogen laser (337 nm). During experiments $0.5 \mathrm{mg}$ of solid samples were deposited on a stainless steel target plate, rubbed over the surface by using a spatula and analysed.

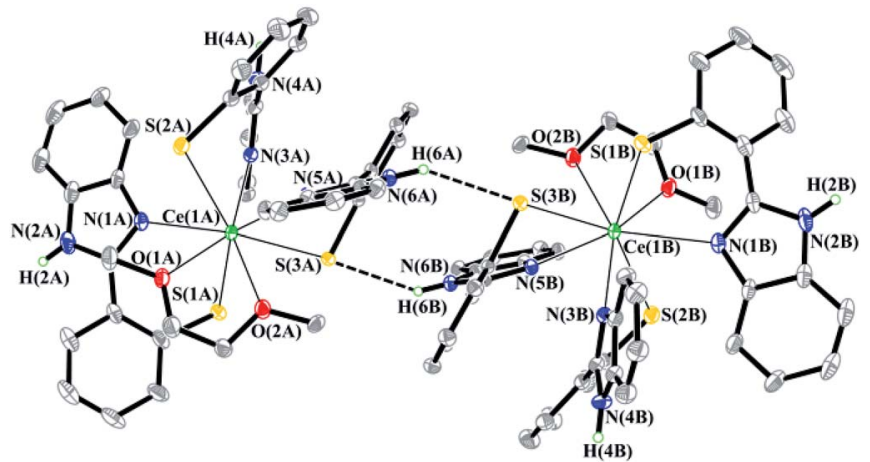

Fig. 3 Fragment of crystal packing of the $\mathrm{Ce}(\mathrm{NSN})_{3}(\mathrm{DME})$ complex. Some hydrogen atoms and non-coordinated DME molecules are omitted for clarity.

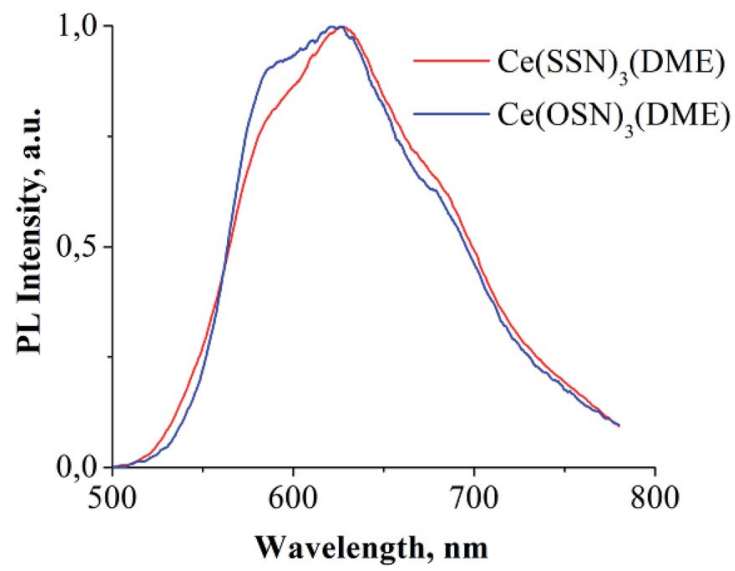

Fig. $4 \mathrm{PL}$ spectra of solid complexes $\mathrm{Ce}(\mathrm{OSN})_{3}(\mathrm{DME})$ and $\mathrm{Ce}(\mathrm{SSN})_{3}(\mathrm{DM})$. Excitation - $405 \mathrm{~nm}$ laser diode.

\section{Synthetic procedures}

H(OSN) (2-(2'-mercaptophenyl)benzoxazole). $o$-Aminophenol (2.18 g, $20 \mathrm{mmol})$ and thiosalicylic acid (3.08 g, 20 $\mathrm{mmol}$ ) were put in $100 \mathrm{~mL}$ two-neck flask. The mixture was blown with argon and then $50 \mathrm{~mL}$ of toluene was added. The

$\mathbf{a}$

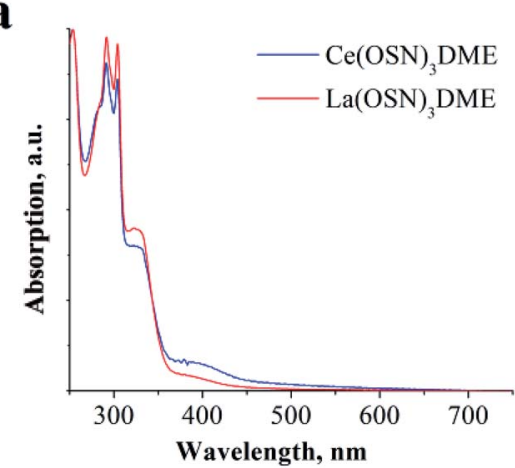

b 
flask was mixed with a magnetic stirrer for 10 minutes, and then phosphorus trichloride $(1.75 \mathrm{~mL}, 20 \mathrm{mmol})$ was added dropwise for 10 minutes at $40-60{ }^{\circ} \mathrm{C}$. The mixture was refluxed for 4 hours with argon atmosphere. Then reaction mixture was cooled at the room temperature and volatile products were rotary evaporated. Remaining viscous product was sublimed twice (125$\left.150{ }^{\circ} \mathrm{C} ; 1 \times 10^{-3} \mathrm{mbar}\right)$ to give $923 \mathrm{mg}$ of $\mathbf{H}(\mathbf{O S N})(20.6 \%)$ as light-beige powder. IR (Nujol, $\mathrm{cm}^{-1}$ ): 2320 (br), 1679 (w), 1589 (m), 1561 (w), 1539 (m), 1339 (w), 1272 (m), 1243 (s), 1196 (m), 1092 (w), 1032 (s), 925 (m), 864 (w), 816 (s), 695 (w), 655 (w), 627 (w) (Fig. 3S $\dagger$ ). Mass spectra: $m / z=227$. Elemental analysis: found $\mathrm{C}, 68.73 ; \mathrm{H}, 3.95 ; \mathrm{N}, 6.19 ; \mathrm{S}, 14.12$ for $\mathrm{C}_{13} \mathrm{H}_{9} \mathrm{NOS}$ : calculated C, 68.70; H, 3.99; N, 6.16; S, 14.11.

H(SSN) (2-(2'-mercaptophenyl)benzothiazole). The synthesis was realized similarly to $\mathbf{H}(\mathbf{O S N})$ from $o$-aminothiophenol (2.14 $\mathrm{mL}, 20 \mathrm{mmol})$, thiosalicylic acid $(3.08 \mathrm{~g}, 20 \mathrm{mmol})$ and phosphorus trichloride $(1.75 \mathrm{~mL}, 20 \mathrm{mmol})$ the product was isolated in $41.9 \%$ yield ( $2 \mathrm{~g}$ ) as orange-red powder. IR (Nujol, $\mathrm{cm}^{-1}$ ): 2320 (br), $1586(\mathrm{w}), 1555$ (w), $1314(\mathrm{~m}), 1243(\mathrm{~m}), 1222(\mathrm{w}), 1212(\mathrm{~m})$, 1041 (m), 965 (s), 939 (s), 858 (w), 854 (s), 690 (m), 650 (w), 625 (w) (Fig. 3S $\dagger$ ). Mass spectra: $m / z=243$. Elemental analysis: found C, 64.18; H, 3.75; N, 5.79; S, 26.36 for $\mathrm{C}_{13} \mathrm{H}_{9} \mathrm{NS}_{2}$ : calculated C, 64.16; H, 3.73; N, 5.76; S, 26.35.

H(NSN) (2-(2'-mercaptophenyl)benzimidazole). A mixture of thiosalicylic acid $(3.08 \mathrm{~g}, 20 \mathrm{mmol})$ and $o$-phenylenediamine $(2.16 \mathrm{~g}, 20 \mathrm{mmol})$ was stirred in polyphosphoric acid $(50 \mathrm{~mL})$ at a temperature of $220{ }^{\circ} \mathrm{C}$ for $5 \mathrm{~h}$. Then the reaction mixture was cooled to the room temperature and solved in ice-cold water. Then sodium hydrocarbonate was added until neutral or alkalescent $\mathrm{pH}$. The precipitate was filtered, dried in vacuum and sublimed to give $\mathbf{H}$ (NSN) as yellow powder in $21 \%$ yield $(0.95 \mathrm{~g})$. Elemental analysis: found $\mathrm{C}, 69.03 ; \mathrm{H}$, $4.51 ; \mathrm{N}, 12.32 ; \mathrm{S}, 14.16$ for $\mathrm{C}_{13} \mathrm{H}_{10} \mathrm{~N}_{2} \mathrm{~S}$ : calculated C, 69.00; $\mathrm{H}$, 4.45; N, 12.38; S, 14.17. IR (Nujol, $\mathrm{cm}^{-1}$ ): 3055 (w), 2300 (br), $1942(\mathrm{w}), 1728(\mathrm{w}), 1690(\mathrm{w}), 1587(\mathrm{w}), 1556(\mathrm{~m}), 1495(\mathrm{w})$, 1315 (m), 1243 (m), 1215 (m), 968 (m), $946(\mathrm{~m}), 752$ (s), 690 (m). Mass spectra: $m / z=226$.

$\mathrm{Ce}(\mathrm{OSN})_{3}(\mathrm{DME})$. A mixture of 2-(2'-mercaptophenyl)benzoxazole (H(OSN)) (170.5 mg, $0.75 \mathrm{mmol})$ and $\mathrm{Ce}\left[\mathrm{N}\left(\mathrm{SiMe}_{3}\right)_{2}\right]_{3}$ $(155.1 \mathrm{mg}, 0.25 \mathrm{mmol})$ in DME solution $(10 \mathrm{~mL})$ was stirred at the room temperature for 30 minutes. Then the volatile products were rotary evaporated. Solid precipitate was washed with hexane and dried in vacuum for 1 hour at the room temperature. Product (Ce(OSN) $)_{\mathbf{3}}$ (DME)) was isolated as orange powder in $89 \%$ yield $(202.2 \mathrm{mg})$. Elemental analysis: found $\mathrm{C}$, $56.84 ; \mathrm{H}, 3.72 ; \mathrm{N}, 4.65 ; \mathrm{S}, 10.60$; Ce, 15.40 for $\mathrm{C}_{43} \mathrm{H}_{34} \mathrm{~N}_{3} \mathrm{O}_{5} \mathrm{~S}_{3} \mathrm{Ce}$ : calculated $\mathrm{C}, 56.81 ; \mathrm{H}, 3.77 ; \mathrm{N}, 4.62 ; \mathrm{S}, 10.58$; Ce, 15.41. IR (Nujol, cm ${ }^{-1}$ ): 1601 (m), 1584 (m), 1550 (m), 1519 (m), 1415 (m), 1240 (s), $1190(\mathrm{~m}), 1134$ (m), 1044 (s), 1018 (w), $1004(\mathrm{w})$, 861 (s), 813 (s), $653(\mathrm{~m}), 627(\mathrm{~m}), 560$ (m) (Fig. 3S†). Crystals used for X-ray analysis were obtained by crystallization from DME solution.

$\mathbf{C e}(\mathbf{S S N})_{3}(\mathrm{DME})$. The synthesis was realized similarly to Ce(OSN) $)_{3}$ (DME) from 2-(2'-mercaptophenyl)benzothiazole $\left(\mathbf{H}(\mathbf{S S N})\right.$ ) (and $182.3 \mathrm{mg}, 0.75 \mathrm{mmol}$ ) and $\mathrm{Ce}\left[\mathrm{N}\left(\mathrm{SiMe}_{3}\right)_{2}\right]_{3}$ (155.1 $\mathrm{mg}, 0.25 \mathrm{mmol})$. Product $\left(\mathrm{Ce}(\mathrm{SSN})_{3}(\mathrm{DME})\right)$ was isolated as yellow-orange powder in $92 \%$ yield $(220.1 \mathrm{mg})$. Elemental analysis: found C, 53.98; H, 3.59; N, 4.40; S, 20.13; Ce, 14.62 for $\mathrm{C}_{43} \mathrm{H}_{34} \mathrm{~N}_{3} \mathrm{O}_{2} \mathrm{~S}_{6}$ Ce: calculated C, 53.95; H, 3.58; N, 4.39; S, 20.10; $\mathrm{Ce}, 14.64$. Crystals used for X-ray analysis was obtained by crystallization from DME solution. IR (Nujol, $\left.\mathrm{cm}^{-1}\right)$ : 1581 (m), 1561 (w), 1547 (w), 1409 (w), 1322 (m), 1249 (w), 1201 (s), 1106 (s), 1052 (s), 970 (s), 861 (s), 760 (s), 700 (m), 690 (m), 644 (m) (Fig. 3S†).

$\mathrm{Ce}(\mathrm{NSN})_{3}$ (DME). A mixture of 2-(2'-mercaptophenyl)benzimidazole (H(NSN)) $(170 \mathrm{mg}, 0.75 \mathrm{mmol})$ and $\mathrm{Ce}\left[\mathrm{N}\left(\mathrm{SiMe}_{3}\right)_{2}\right]_{3}$ $(155.1 \mathrm{mg}, 0.25 \mathrm{mmol})$ in DME solution $(10 \mathrm{~mL})$ was stirred in ultrasonic bath for 10 hours at the room temperature. Then volatile products were rotary evaporated. Solid precipitate was washed with hexane and dried in vacuum for 1 hour at the room temperature. Product $\left(\mathbf{C e}(\mathbf{N S N})_{3}(\mathbf{D M E})\right)$ was isolated as yellow-orange powder in $86 \%$ yield $(195.0 \mathrm{mg})$. Elemental analysis: found C, 57.02; H, 4.15; N, 9.30; S, 10.60; Ce, 15.41 for $\mathrm{C}_{43} \mathrm{H}_{37} \mathrm{~N}_{6} \mathrm{O}_{2} \mathrm{~S}_{3} \mathrm{Ce}$ : calculated $\mathrm{C}, 57.00 ; \mathrm{H}, 4.12 ; \mathrm{N}$, 9.27; S, 10.62; Ce, 15.46. Crystals used for X-ray analysis were obtained by crystallization from DME solution.

$\mathbf{L a}(\mathbf{O S N})_{3}$ (DME). The synthesis was realized similarly to Ce(OSN) $)_{3}$ (DME) from 2-(2'-mercaptophenyl)benzoxazole (H(OSN)) (170.5 mg, $0.75 \mathrm{mmol})$ and $\mathrm{La}\left[\mathrm{N}\left(\mathrm{SiMe}_{3}\right)_{2}\right]_{3}(155.0 \mathrm{mg}$, $0.25 \mathrm{mmol})$. Product $\left(\mathbf{L a}(\mathbf{O S N})_{3}(\mathbf{D M E})\right)$ was isolated as lemonyellow powder in $91 \%$ yield $(206.5 \mathrm{mg})$. Elemental analysis: found $\mathrm{C}, 56.85 ; \mathrm{H}, 3.71 ; \mathrm{N}, 4.65 ; \mathrm{S}, 10.60 ; \mathrm{La}, 15.25$ for $\mathrm{C}_{43^{-}}$ $\mathrm{H}_{34} \mathrm{~N}_{3} \mathrm{O}_{5} \mathrm{~S}_{3}$ La: calculated C, 56.89; H, 3.77; N, 4.63; S, 10.60; La, 15.30. IR spectrum of $\mathbf{L a}(\mathbf{O S N})_{3}(\mathrm{DME})$ is identical to that of $\mathrm{Ce}(\mathrm{OSN})_{3}(\mathrm{DME})$. Crystals used for X-ray analysis were obtained by crystallization from DME solution.

\section{X-ray}

The X-ray diffraction data for the complexes were collected on a Bruker AXS SMART APEX (Ce(SSN) $)_{3}($ DME)) and Oxford Xcalibur Eos ( $\left.\mathbf{L a}(\mathbf{O S N})_{3}(\mathrm{DME}), \mathbf{C e}(\mathrm{NSN})_{\mathbf{3}}(\mathrm{DME})\right)$ diffractometers $\left(\right.$ Mo-K $_{\alpha}$ radiation, $\omega$-scan technique, $\lambda=0.71073 \AA$ ). The intensity data were integrated by SAINT $\left(\mathrm{Ce}(\mathrm{SSN})_{\mathbf{3}}(\mathrm{DME})\right)^{\mathbf{4 5}}$ and CrysAlisPro $\left(\mathrm{La}(\mathrm{OSN})_{3}(\mathrm{DME}), \quad \mathrm{Ce}(\mathrm{NSN})_{3}(\mathrm{DME})\right)^{\mathbf{4 6}}$ programs. SADABS $\left(\mathbf{C e}(\mathbf{S S N})_{3}(\mathbf{D M E})\right)^{47}$ and SCALE3 ABSPACK $(\text { La(OSN) })_{3}(\text { DME), Ce(NSN) })_{3}($ DME $\left.)\right)^{48}$ programs were used to perform absorption corrections. The $\mathbf{L a}(\mathbf{O S N})_{3}(\mathbf{D M E})$ complex was solved by direct method and $\mathbf{C e}(\mathbf{N S N})_{3}(\mathrm{DME})$ and $\mathbf{C e}(\mathbf{S S N})_{3}(\mathrm{DME})$ complexes were solves by dual method. ${ }^{\mathbf{4 9}}$ All structures were refined on $F_{h k l}{ }^{2}$ using SHELXTL package. ${ }^{50}$ All non-hydrogen atoms were refined anisotropically. All hydrogen atoms were placed in calculated positions and were refined in the riding model $\left(\mathrm{U}_{\text {iso }}(\mathrm{H})=1.5 \mathrm{U}_{\text {eq }}(\mathrm{C})\right.$ for $\mathrm{CH}_{3}$ groups and $\mathrm{U}_{\mathrm{iso}}(\mathrm{H})=1.2 \mathrm{U}_{\mathrm{eq}}(\mathrm{C}, \mathrm{N})$ for other groups $)$. The main crystallographic data and structure refinement details for $\mathrm{Ce}(\mathrm{NSN})_{3}(\mathrm{DME}), \quad \mathrm{La}(\mathrm{OSN})_{3}(\mathrm{DME}), \mathrm{Ce}(\mathrm{SSN})_{3}(\mathrm{DME})$ are presented in Table $1 \mathrm{~S} . \dagger$ The asymmetric unit of $\mathbf{C e}(\mathbf{S S N})_{3}(-$ DME) contains a solvate molecule of DME whereas the crystals of $\mathbf{C e}(\mathbf{N S N})_{3}(\mathrm{DME})$ contain 1.25 disordered molecules of DME per one complex molecule.

CCDC 1907215 (La(OSN) $)_{3}$ (DME)), 1907216 (Ce(NSN) $\left.)_{3}(\mathrm{DME})\right)$ and $1907217\left(\mathbf{C e}(\mathbf{S S N})_{3}(\mathbf{D M E})\right)$ contain the supplementary crystallographic data. $\dagger$ 


\section{Conclusions}

In summary, we have synthesized a set of novel Ce(III) complexes with azolyl-substituted thiophenolate ligands - 2-(2'-mercaptophenyl)benzimidazole (NSN(H)), 2-( $2^{\prime}$-mercaptophenyl)benzoxazole $\quad(\mathbf{O S N}(\mathbf{H}))$ and 2 - $\left(2^{\prime}\right.$-mercaptophenyl)benzothiazole (SSN(H)). The lanthanum complex with OSN ligand has been also synthesized to be used as a reference compound. The data of X-ray and MALDI-TOF revealed that all the synthesized complexes are monomeric species which contain three anionic thiophenolate ligands and one coordinated neutral DME molecule. It was found that $\mathrm{Ce}(\mathrm{OSN})_{3}(\mathrm{DME})$ and $\mathrm{Ce}(\mathrm{SSN})_{3}(-$ DME) in the solid state exhibit the PL peaked at $620 \mathrm{~nm}$. This is the maximal wavelength ever observed for $\mathrm{f}-\mathrm{d}$ luminescent $\mathrm{Ce}$ (III) molecular complexes. But no red PL is observed in the solutions of these complexes that is caused, apparently, by the blue shift of the $\mathrm{f}-\mathrm{d}$ transitions. We believe that synthesis of novel molecular $\mathrm{Ce}$ (III) $\mathrm{f}-\mathrm{d}$ luminophores with long-lived and low-energy $5 \mathrm{~d}$ states would become a modern challenge in coordination chemistry because these compounds will be useful as red or infrared emitters and can replace noble metal derivatives in photoredox catalyzed processes.

\section{Conflicts of interest}

There are no conflicts to declare.

\section{Acknowledgements}

This work was supported by the Russian Foundation for Basic Research (project no. 18-33-20103). The structure of the complexes was defined in the Framework of the Russian State Assignment (Theme 45.6, Reg. N AAAA-A19-119011690055-0). The work was performed using the instrumental base of the Analytical Center of the G. A. Razuvaev Institute of Organometallic Chemistry, Russian Academy of Sciences. The analysis of complexes using MALDI mass spectrometry was done in accordance with the task of Ministry of Science and Higher Education of Russia (task 4.5706.2017/B).

\section{References}

1 I. Hernandez and W. P. Gillin, Handbook on the Physics and Chemistry of Rare Earths, 2015, vol. 47, p. 1.

2 J.-C. Bünzli, Handbook on the Physics and Chemistry of Rare Earths, 2016, vol. 50, p. 141.

3 E. M. Chan, Chem. Soc. Rev., 2015, 44, 1653.

4 L. Wang, Z. Zhao, C. Wei, H. Wei, Z. Liu, Z. Bian and

C. Huang, Adv. Opt. Mater., 2019, 7, 1801256.

5 A. P. Pushkarev and M. N. Bochkarev, Russ. Chem. Rev., 2016, 85, 1338.

6 M. A. Katkova and M. N. Bochkarev, Dalton Trans., 2010, 39, 6599.

7 J.-C. Bünzli and A.-S. Chauvin, Handbook on the Physics and Chemistry of Rare Earths, 2014, vol. 44, p. 169.

8 J.-C. G. Bunzli, Eur. J. Inorg. Chem., 2017, 5058.
9 H. Li, C. Xie, R. Lan, S. Zha, C.-F. Chan, W.-Y. Wong, K.-L. Ho, B. D. Chan, Y. Luo, J.-X. Zhang, G.-L. Law, W. C. S. Tai, J.-C. G. Bünzli and K.-L. Wong, J. Med. Chem., 2017, 60, 8923.

10 J.-C. G. Bünzli, J. Lumin., 2016, 170, 866.

11 J.-C. G. Bunzli, Luminescence Bioimaging with Lanthanide Complexes, Luminescence of Lanthanide Ions in Coordination Compounds and Nanomaterials, Wiley, 1st edn, 2014, vol. 4, p. 125.

12 X. Qin, X. Liu, W. Huang, M. Bettinelli and X. Liu, Chem. Rev., 2017, 117, 4488.

13 G. Li, Y. Tian, Y. Zhaoa and J. Lin, Chem. Soc. Rev., 2015, 44, 8688.

14 Y. Qiao and E. J. Schelter, Acc. Chem. Res., 2018, 51, 2926.

15 H. Yin, P. J. Carroll, B. C. Manor, J. M. Anna and E. J. Schelter, J. Am. Chem. Soc., 2016, 138, 5984.

16 J.-J. Guo, A. Hu, Y. Chen, J. Sun, H. Tang and Z. Zuo, Angew. Chem., Int. Ed., 2016, 55, 15319.

17 R. Konduri, H. Ye, F. M. MacDonnell, S. Serroni, S. Campagna and K. Rajeshwar, Angew. Chem., 2002, 114, 3317.

18 S. H. Lee, J. H. Kim and C. B. Park, Chem.-Eur. J., 2013, 19, 4392.

19 N. A. Till, R. T. Smith and D. W. C. MacMillan, J. Am. Chem. Soc., 2018, 140, 5701.

20 H. Xiang, J. Cheng, X. Ma, X. Zhou and J. Chruma, Chem. Soc. Rev., 2013, 42, 6128.

21 H. Yin, P. J. Carroll and E. J. Schelter, J. Am. Chem. Soc., 2015, 137, 9234.

22 D. M. Kuzyaev, T. V. Balashova, M. E. Burin, G. K. Fukin, R. V. Rumyantcev, A. P. Pushkarev, V. A. Ilichev, I. D. Grishin, D. L. Vorozhtsov and M. N. Bochkarev, Dalton Trans., 2016, 45, 3464.

23 P. N. Hazin, C. Lakshminarayan, L. S. Brinen, J. L. Knee, J. W. Bruno, W. E. Streib and K. Folting, Inorg. Chem., 1988, 27, 1393.

24 P. N. Hazin, J. W. Bruno and H. G. Brittain, Organometallics, 1987, 6, 913.

25 M. D. Rausch, K. J. Moriarty, J. L. Atwood, J. A. Weeks, W. E. Hunter and H. G. Brittain, Organometallics, 1986, 5, 1281.

26 X.-L. Zheng, Y. Liu, M. Pan, X.-Q. Lu, J.-Y. Zhang, C.-Y. Zhao, Y.-X. Tong and C.-Y. Su, Angew. Chem., Int. Ed., 2007, 46, 7399.

27 A. Baschieri, A. Mazzanti, S. Stagni and L. Sambri, Eur. J. Inorg. Chem., 2013, 2432.

28 M. E. Azenha, H. D. Burrows, S. M. Fonseca, M. L. Ramos, J. Rovisco, J. S. de Melo, A. J. F. N. Sobrala and K. Kogejb, New J. Chem., 2008, 32, 1531.

29 H. Kunkely and A. Vogler, J. Photochem. Photobiol., A, 2002, 151, 45.

30 P. R. Matthes and K. Müller-Buschbaum, Z. Anorg. Allg. Chem., 2014, 640, 2847.

31 Y. Jiao, J. Wang, P. Wu, L. Zhao, C. He, J. Zhang and C. Duan, Chem.-Eur. J., 2014, 20, 2224.

32 T. Yu, W. Su, W. Li, R. Hua, B. Chu and B. Li, Solid-State Electron., 2007, 51, 894. 
33 P. Dorenbos, Phys. Rev. B: Condens. Matter Mater. Phys., 2000, 62, 15640.

34 P. Dorenbos, Phys. Rev. B: Condens. Matter Mater. Phys., 2000, 62, 15650.

35 P. Dorenbos, Phys. Rev. B: Condens. Matter Mater. Phys., 2001, 64, 125117-1.

36 V. A. Ilichev, A. V. Rozhkov, R. V. Rumyantcev, G. K. Fukin, I. D. Grishin, A. V. Dmitriev, D. A. Lypenko, E. I. Maltsev, A. N. Yablonskiy, B. A. Andreev and M. N. Bochkarev, Dalton Trans., 2017, 46, 3041.

37 C. Janiak, J. Chem. Soc., Dalton Trans., 2000, 3885.

38 M. Roger, N. Barros, T. Arliguie, P. Thuery, L. Maron and M. Ephritikhine, J. Am. Chem. Soc., 2006, 128, 8790.

39 J. H. Melman, C. Rohde, T. J. Emge and J. G. Brennan, Inorg. Chem., 2002, 41, 28.

40 S. Bannerjee, T. J. Emge and J. G. Brennan, Inorg. Chem., 2000, 43, 6307.

41 T. Lathion, L. Guenee, C. Besnard, A. Bousseksou and C. Piguet, Chem.-Eur. J., 2018, 24, 16873.
42 G. B. Deacon, P. C. Junk and A. Urbatsch, Eur. J. Inorg. Chem., 2011, 3592.

43 J. Donohue, J. Mol. Biol., 1969, 45, 231.

44 A. Vogler and H. Kunkley, Inorg. Chim. Acta, 2006, 359, 4130. 45 SAINT, Data Reduction and Correction Program v. 8.27B, Bruker AXS, Madison, Wisconsin, USA, 2014.

46 Data Collection, Reduction and Correction Program. Version 1.171.37.35, CrysAlisPro - Software Package, Agilent Technologies, 2012.

47 L. Krause, R. Herbst-Irmer, G. M. Sheldrick and D. Stalke, J. Appl. Crystallogr., 2015, 48, 3.

48 R. C. Clark and J. S. Reid, Acta Crystallogr., Sect. A: Found. Crystallogr., 1995, 51, 887.

49 G. M. Sheldrick, Acta Crystallogr., Sect. A: Found. Adv., 2015, 71, 3 .

50 G. M. Sheldrick, Acta Crystallogr., Sect. C: Struct. Chem., 2015, $71,3$. 